Reviews in Digital Humanities • Vol. 3, No. 1

\title{
Review: Digital Oral Histories for Reconciliation
}

\author{
Jasmine Clark ${ }^{1}$
}

${ }^{1}$ Temple University

Published on: Jan 18, 2022

DOI: 10.21428/3e88f64f.ab882336

License: Creative Commons Attribution 4.0 International License (CC-BY 4.0). 


\section{Project}

Digital Oral Histories for Reconciliation (DOHR)

\section{Project Leads}

Kristina Llewellyn, Project Director and Oral History Cluster Lead, University of Waterloo

Jennifer Roberts-Smith, Virtual Reality Cluster Lead, Creative Director, University of Waterloo

Lindsay Gibson, History Education Cluster Lead, University of British Columbia Jennifer J. Llewellyn, Restorative Pedagogy Cluster Lead, Dalhousie University Tracy Dorrington-Smith, Storyteller, Victims of Institutional Childhood Exploitation Society Gerry Morrison, Storyteller, Victims of Institutional Childhood Exploitation Society Tony Smith, Storyteller, Victims of Institutional Childhood Exploitation Society

\section{Project URL}

https://dohr.ca/

https://dohrprojectca.wordpress.com/

\section{Project Reviewer}

Jasmine Clark, Temple University

\section{Project Overview}

\section{Jennifer Roberts-Smith and Arda Kizilcay}

In partial fulfillment of the public education mandate of the Nova Scotia Restorative Inquiry into the harms suffered by former residents of the Nova Scotia Home for Coloured Children (NSHCC), the Digital Oral Histories for Reconciliation (DOHR) project created a two-week, restorative, anti-racist curriculum for Grade 11 Canadian History students. Its centerpiece is a virtual reality rendering of the oral histories of former residents of the NSHCC, called The Home: The Digital Oral Histories for Reconciliation Virtual Reality Experience. The Home was designed, developed, and tested over four years, in an ongoing collaboration with three former residents, Gerry Morrison, Tony Smith, and Tracy Dorrington-Skinner, who are recognized leaders and activists in the community. Morrison, Smith, and Dorrington-Skinner have been involved in all activities from conception through design, development, testing, and 
revision. They have sign-off authority on all elements of The Home, as well as its distribution.

The entire experience takes about 14-16 minutes to complete. Not all content can be experienced in a single viewing; there are four stories from each of the storytellers, but participants can witness a maximum of one from each storyteller in a single viewing. Multiple viewings are required to witness all of the stories. (This function was designed to encourage students, who were permitted one viewing only, to share their differing experiences with one another.)

We think of The Home as an evolving research prototype. Research prototypes are artifacts or experiences made in order to articulate conjectures about possible futures and determine whether and how to try to bring those futures into being (Zaki Warfel 2009; Viswanathan and Linsey 2012; Ruecker and Roberts-Smith 2018; Roberts-Smith, Radzikowska, and Ruecker 2021). Some research prototypes are purely speculative and need not be distributed publicly in order to challenge existing knowledge and practices (Boer and Donovan 2012; Dunne and Raby 2013); others are experimental, intended to instantiate particular ideas in order to understand them better (Ruecker 2015; Aikman, Roberts-Smith, and Ruecker 2021); some are production-oriented, intended to determine the best design for a product to be released to the public (Brown 2009).

In its first iteration (the Alpha Release), The Home operated as a speculative prototype, which aimed to challenge received wisdom about best practices in virtual reality design, in the context of restorative justice. The experimental Beta and Pilot Releases instantiated a new approach to designing virtual learning environments (VLEs) called "relational presence" (Roberts-Smith, Carpenter et al. 2020), which is based on the guiding principles of the NSHCC Restorative Inquiry and the practice of restorative pedagogy (Llewellyn and Llewellyn 2015). In its Review release, The Home has operated as a production prototype, refined for a future, full implementation of the DOHR Curriculum. All four iterations have been tested in different ways: Alpha teaminternally; Beta with partner communities; Pilot with students, teachers, and support workers in two Nova Scotia schools; and Review in this submission.

A final, user-ready product iteration, the Curriculum Release, is anticipated for implementation in all Grade 11 Canadian History courses in Nova Scotia in 2022-23. New funding has also recently been secured to support a permanent exhibit including new haptic (touch-based) elements at the Nova Scotia Black Cultural Centre. As a result, a Museum Release is also anticipated in 2022-3. 
We have been guided in our approach to data management by the University of Victoria's Endings for Sustainable Digital Humanities project and are working towards compliance with the Endings recommendations. To date, data and code have been subject to version control; we use the open-access Unity game engine; we have developed a preliminary data model describing all static assets, their access restrictions, and IP; and we have maintained a periodical release plan. The Home's code and digital assets have been inventoried and archived for long term storage on the University of Waterloo Games Institute's servers.

\section{References}

Aikman, Lisa, Jennifer Roberts-Smith, and Stan Ruecker, with Kate Crozier, Jessica Hutchison, Carin Lowerison, Signy Lynch, May Nemat Allah, Julie Thompson, Matt White, and Hannah Watts. Forthcoming 2021. "Theatre for Relationality: A Relational Approach to Design Research." In Impacting Audiences, edited by Matt Omasta and Dani Snyder-Young. Oxfordshire: Routledge.

Boer, Laurens and Jared Donovan. "Provotypes for Participatory Innovation”, in Proceedings of the Designing Interactive Systems Conference (DIS '12). 388-397. New York: ACM.

Brown, T. 2009. Change by Design: How Design Thinking Transforms Organizations and Inspires Innovation. New York: HarperCollins.

Dunne, A. and Raby, F. 2013. Speculative Everything: Design, Fiction, and Social Dreaming. Cambridge, MA: MIT Press.

Llewellyn, Kristina, and Jennifer J. Llewellyn. 2015. "A Restorative Approach to Learning: Relational Theory as Feminist Pedagogy in Universities," in Feminist Pedagogy in Higher Education: Critical Theory and Practice, edited by Tracy Penny Light, Jane Nicholas, and Renée Bondy. Waterloo, ON: Wilfred Laurier University Press. 11-31.

Roberts-Smith, Jennifer and Justin Carpenter, with Kristina R. Llewellyn, Jennifer J. Llewellyn, Tracy Dorrington-Skinner, Gerald Morrison, Tony Smith, and the DOHR Research Team. 2020. "Relational Presence: Designing VR-based Virtual Learning Environments for Oral History-based Pedagogy." Special Issue: Extended Reality. Ed. Amanda Licastro, Victoria Szabo, and Angel David Nieves. Journal of Interactive Technology and Pedagogy, no. 17: n.p. https://jitp.commons.gc.cuny.edu/relational- 
presence-designing-vr-based-virtual-learning-environments-for-oral-history-basedrestorative-pedagogy $\perp$

Roberts-Smith, Jennifer, Milena Radzikowska, and Stan Ruecker, eds. 2021.

Prototyping Across the Disciplines: Designing Better Futures. Fishponds, Bristol: Intellect Books.

Ruecker, Stan. 2015. "A Brief Taxonomy of Prototypes for the Digital Humanities." Scholarly and Research Communication 6.2: 0201222.

Ruecker, Stan and Jennifer Roberts-Smith. 2018. “Design Research: Objects, Procedures, and New Understanding." Technology / Architecture + Design 2, no.1: 1114.

Viswanathan, V. K. and Linsey, J. S. 2012. "Physical models and design thinking: A study of functionality, novelty and variety of ideas." Journal of Mechanical Design, no. 134: 091004-1- 091004- 13.

Zaki Warfel, T. 2009. Prototyping: A Practitioner's Guide. Brooklyn, NY: Rosenfeld Media.

\section{Project Review}

\section{Jasmine Clark}

The Home: The Digital Oral Histories for Reconciliation (DOHR) virtual reality (VR) experience is part of a two-week, restorative, anti-racist curriculum for Grade 11 Canadian History students. As part of the public education mandate of the Nova Scotia Restorative Inquiry into the harms suffered by former residents of the Nova Scotia Home for Coloured Children (NSHCC), it shares the stories of three former NSHCC residents: Gerry Morrison, Tony Smith, and Tracy Dorrington-Skinner.

The VR experience, built as a Unity 3D application available for use on the Oculus Rift, Rift S, Quest, and Quest 2, opens with video of the three former residents reuniting at the school as portions of their stories play in the background. As their stories converge, the user is able to use a hand controller to select one of their narratives. The video converts into a 3D modeled environment that focuses on recreating the spaces, sounds, and tone of events described. Some of the stories contain sexual abuse and violence. In these cases, actual violence is not shown but disheveled spaces that strongly evoke the aftermath of a violent event, along with the sounds of muted 
arguing and written quotes that appear as graffiti on the walls, create an uneasiness and distance that affirms the horror of the events being described. This distance between the user and the narrative is a strength for this type of content. Experiences dealing with such serious subjects should not lead students to believe that they understand what it was like to go through the described events because they "embodied" the trauma of another. Instead, this narrative approach emphasizes emotional impact while avoiding a sense of voyeurism.

There is a clear, conscious approach to the way the project manages the agency of the former residents, students, and those involved in facilitating use of the experience. There is an emphasis on explicit consent from the former residents regarding how the stories are presented, how and where the project is shared, and how the former residents are credited. There are detailed onboarding protocols that account for disability, sanitation, varying levels of familiarity with VR, and consent (students can opt out of stories with sexual abuse), and that provide guidance for those working with the students. There is a high level of transparency regarding how these stories were sourced, the nature of their content, how they will be used, and the technical and environmental requirements for using this experience.

This is all further strengthened by a very hands-on, human-centered, guided learning approach. Onboarding is conducted in-person. Included among the accompanying learning activities are group discussions, card-sorting activities, journaling, and personal reflection. Africentric curricular frameworks are explicitly utilized with an emphasis on "Sankofa," a Twi word that means "it is not forbidden to fetch what is at risk of being left behind" and that is commonly used in Afri/Afro-centric education. The DOHR VR experience is a strong example of a restorative pedagogical VR project. It is ethically responsible regarding the people involved, narratively proficient, and pedagogically grounded in established educational frameworks. 